S.A. Dupont, MD, PhD

A. Dispenzieri, MD

M.L. Mauermann, MD

A.A. Rabinstein, $M D$

R.D. Brown, Jr., MD, $\mathrm{MPH}$

Address correspondence and reprint requests to Dr. Stefan A. Dupont, Department of Neurology, Mayo Clinic, 200 First St SW, Rochester, MN 55905

dupont.stefan@mayo.edu

\section{Cerebral infarction in POEMS syndrome}

\author{
Incidence, risk factors, and imaging characteristics
}

\section{ABSTRACT}

Objectives: To determine the risk factors and incidence of cerebral infarction associated with POEMS (polyneuropathy, organomegaly, endocrinopathy, monoclonal gammopathy, and skin changes) syndrome.

Methods: The Mayo Clinic dysproteinemia database was queried to identify patients with coded diagnosis of POEMS syndrome. Patients with cerebral infarction, occurring after the onset of POEMS-related symptoms, were selected. A retrospective observational study design was used to evaluate potential predictors of stroke in patients with POEMS syndrome.

Results: A total of 9 patients (10\%; 95\% confidence interval 5.4-17.9) with cerebral infarction were identified (2 women, 22\%). Traditional stroke risk factors were not significantly different between the stroke and nonstroke subgroups, but hematologic abnormalities such as elevated platelet count and bone marrow plasmacytosis differed between the 2 groups. Cerebral infarction occurrence after successful treatment of the underlying condition was not observed. CT and MRI data demonstrated a wide spectrum of infarct topography in these patients. Common stroke etiologies comprised suspected vascular structural abnormalities leading to vessel dissection and stenosis, in addition to embolism from a proximal source.

Conclusions: The 5-year risk of cerebral infarction in patients with POEMS syndrome is 13.4\%. Evidence of plasma cell proliferation within the bone marrow and elevated serum platelet count led to increased risk of cerebral infarction in this population. We conclude that known modifiable stroke risk factors should be aggressively managed. Treatment of thrombocytosis should be considered in patients without a contraindication. Treatment of the syndrome may be the best approach to decreasing risk of cerebral infarction in these patients. Neurology ${ }^{\circledR} 2009 ; 73: 1308-1312$

\section{GLOSSARY}

$\mathbf{C l}=$ confidence interval; FSRP = Framingham Stroke Risk Profile; POEMS = polyneuropathy, organomegaly, endocrinopathy, monoclonal gammopathy, and skin changes; TOAST = Trial of Org 10172 in Acute Stroke Treatment; VEGF = vascular endothelial growth factor.

POEMS syndrome is a disorder associated with an underlying plasma cell dyscrasia. The major clinical features of this syndrome are captured by the acronym and include polyneuropathy, organomegaly, endocrinopathy, monoclonal gammopathy, and skin changes. Other important associated findings include elevated levels of vascular endothelial growth factor (VEGF), Castleman disease, sclerotic bone lesions, papilledema, and thrombocytosis. ${ }^{1}$

The pathogenesis of this multisystemic disease is not yet understood. A protein deposition abnormality, such as that seen in systemic amyloidosis, has not been observed. On the other hand, pathologic studies have demonstrated structural derangements in selected blood vessels. ${ }^{2}$ Therefore, a causative role for the elevated levels of proangiogenic factors seen in this syndrome has been suggested. ${ }^{3}$

Since systemic vasculature is affected in this syndrome, reports of associated ischemic organ injury such as cerebral infarctions should not be surprising. Indeed, cases of cerebral

From the Departments of Neurology (S.A.D., M.L.M., A.A.R., R.D.B.) and Hematology (A.D.), Mayo Clinic, Rochester, MN.

Disclosure: Author disclosures are provided at the end of the article. 
infarction in patients with POEMS syndrome have been reported in the literature. ${ }^{4-8}$ However, whether a direct association exists between the diagnosis of POEMS syndrome and development of cerebral infarction remains unclear. Our study aimed to establish such an association and to determine the incidence and risk factors for cerebral infarction in patients with POEMS syndrome.

METHODS Our institutional dysproteinemia database was used to identify 208 patients with a diagnosis of POEMS syndrome (January 1973-August 2008). As part of a previously published study, ${ }^{1}$ extensive data had already been collected on patients whose diagnosis was made between 1973 and 1999. All patients (or their physicians) for whom no follow-up data were available had been contacted and follow-up data were available for more than $94 \%$ of patients. Complete follow-up information was available for patients diagnosed between January 1, 2000, and August 31, 2008. Al patients were 18 years of age or older and met both major criteria and at least one minor criterion for diagnosis of POEMS syndrome. ${ }^{1}$

The terms cerebral infarction and stroke are used interchangeably in this article. Cerebral infarction was defined as the acute onset of focal neurologic symptoms lasting at least 24 hours, without a nonischemic cause identified. The clinical diagnosis of stroke was verified by CT or MRI. Patients in whom the diagnosis of cerebral infarction preceded any symptoms of peripheral neuropathy were excluded. Cerebral infarctions were categorized according to the Trial of Org 10172 in Acute Stroke Treatment (TOAST) classification scheme ${ }^{9}$ and divided by size of the vessel involved. In addition, events were classified as unilateral, bilateral, supratentorial, infratentorial, or a combination thereof. Detailed clinical description for each stroke was recorded.

The Framingham Stroke Risk Profile (FSRP) score, as previously described, ${ }^{10}$ was calculated for all patients in the cohort. The FSRP was developed using data from 36 years of patient follow-up and includes clinical information (age, systolic blood pressure, antihypertensive therapy use, presence of diabetes, cigarette smoking, history of cardiovascular disease [coronary heart disease or congestive heart failure]) and EKG abnormalities (left ventricular hypertrophy or atrial fibrillation).

A retrospective observational study design was used to identify risk factors for cerebral infarction among patients with a diagnosis of POEMS syndrome, seen at our institution between January 1, 2000, and August 31, 2008. Patients were followed from the onset of peripheral neuropathy to the time of cerebral infarction or their last evaluation. Thrombocytosis was defined as a serum platelet count $>500 \times 10^{9} / \mathrm{L}$. Diagnosis of osteosclerotic lesions was based on imaging studies and did not necessarily include confirmatory biopsies. Bone marrow involvement was assessed based on biopsy results. All statistical analyses were performed using JMP data analysis software (SAS Institute, Cary, NC). $p<0.05$ was considered statistically significant.

The probability of cerebral infarction after onset of peripheral neuropathy symptoms was estimated using the Kaplan-
Table 1 Patient characteristics, stroke risk factors, comorbidities, and serum evaluations in patients with POEMS and cerebral infarction $(n=19)$

\begin{tabular}{|c|c|}
\hline Demographics & Values \\
\hline Median age, y (range) & $53(36-77)$ \\
\hline Male, n (\%) & $12(63)$ \\
\hline \multicolumn{2}{|l|}{ Stroke risk factors, n (\%) } \\
\hline Hypertension & $9(47)$ \\
\hline Hyperlipidemia & $6(32)$ \\
\hline Diabetes & $3(16)$ \\
\hline Smoking within last $3 y$ & $5(26)$ \\
\hline Smoking history & $10(53)$ \\
\hline Family history of stroke at young age & $0(0)$ \\
\hline \multicolumn{2}{|l|}{ Relevant comorbidities, $\mathrm{n}$ (\%) } \\
\hline Atrial fibrillation & $2(11)$ \\
\hline Myocardial infarction & $2(11)$ \\
\hline LVEF $<50$ & $2(11)$ \\
\hline DVT/PE & $4(22)$ \\
\hline Acral gangrene & $2(11)$ \\
\hline \multicolumn{2}{|l|}{ Medications at stroke onset, $n(\%)$} \\
\hline Warfarin & $1(5)$ \\
\hline Antiplatelet agent & $5(26)$ \\
\hline \multicolumn{2}{|l|}{$\begin{array}{l}\text { Laboratory studies at presentation } \\
\text { with stroke }\end{array}$} \\
\hline Hemoglobin (g/dL), mean (SD) & $14.4(1.9)$ \\
\hline WBC (×10\%/L), mean (SD) & $9.2(3.4)$ \\
\hline Platelets (×10\%/L), mean (SD) & 599 (223) \\
\hline $\begin{array}{l}\text { Sedimentation rate }(\mathrm{mm} / \mathrm{h}) \text {, } \\
\text { median (range) }\end{array}$ & $10(1-40)$ \\
\hline Creatinine (mg/dL), median (range) & $1.1(0.5-1.9)$ \\
\hline INR (units), median (range) & $1(0.8-1.2)$ \\
\hline aPTT (s), median (range) & $26(22-35)$ \\
\hline AST (U/L), median (range) & $12(7-31)$ \\
\hline LDH (U/L), median (range) & $110(67-167)$ \\
\hline $\begin{array}{l}\text { Glucose, fasting (mg/dL), median } \\
\text { (range) }\end{array}$ & $96(77-247)$ \\
\hline TSH (mIU/L), median (range) & $5.7(1-21)$ \\
\hline $\begin{array}{l}\text { Cholesterol, total (mg/dL), median } \\
\text { (range) }\end{array}$ & $160(111-227$ \\
\hline Triglycerides (mg/dL), median (range) & $222(78-386)$ \\
\hline HDL (mg/dL), median (range) & $29(16-50)$ \\
\hline LDL (mg/dL), median (range) & $88(38-129)$ \\
\hline
\end{tabular}

POEMS = polyneuropathy, organomegaly, endocrinopathy, monoclonal gammopathy, and skin changes; LVEF = left ventricular ejection fraction; DVT/PE = deep venous thrombosis/ pulmonary embolism; $\mathrm{WBC}=$ white blood cells; INR = international normalized ratio; aPTT $=$ activated partial thromboplastin time; AST = aspartate aminotransferase; $\mathrm{LDH}=$ lactate dehydrogenase; $\mathrm{TSH}=$ thyroid stimulating hormone; HDL = high-density lipoprotein; LDL = low-density lipoprotein 
Meier method with 95\% confidence intervals (CI). The association of baseline variables with the time-dependent outcome of cerebral infarction was assessed using Cox proportional hazards regression. To further explore the association between platelet count and outcome, patients were divided into 3 groups based on tertiles and Kaplan-Meier estimates were reported within each tertile.

Variables showing univariate significance were then included in a multivariable Cox model. In the case of bone marrow plasmacytosis, the hazard ratio could not be estimated as there were no events in patients without bone marrow plasma cell proliferation. Therefore, only a $p$ value estimated by the profile-likelihood method is reported.

Standard protocol approvals, registrations, and patient consents. The study protocol was approved by the Mayo Clinic Institutional Review Board. All patients had signed a written consent to research participation at the time of their initial evaluation.

\begin{tabular}{|c|c|c|c|}
\hline \multirow[t]{2}{*}{$\begin{array}{l}\text { Comparison of patients } \\
\text { syndrome (subgroup as }\end{array}$} & $\begin{array}{l}\text { with and withou } \\
\text { sessed January }\end{array}$ & $\begin{array}{l}\text { ischemic stroke in } \\
2000 \text {-August } 31 \text {, }\end{array}$ & $\begin{array}{l}\text { OEMS } \\
\text { 2008) }\end{array}$ \\
\hline & $\begin{array}{l}\text { Ischemic stroke } \\
(\mathrm{n}=9)\end{array}$ & $\begin{array}{l}\text { No ischemic stroke } \\
(\mathrm{n}=81)\end{array}$ & $p$ Value \\
\hline \multicolumn{4}{|l|}{ Demographics } \\
\hline Age at onset of PN, $y$, median (range) & $46(34-67)$ & $48(20-69)$ & 0.62 \\
\hline Male, n (\%, 95\% Cl) & $7(78,45-94)$ & $56(69,58-78)$ & 0.68 \\
\hline $\mathrm{PN}$ to last $\mathrm{F} / \mathrm{U}$, mo, median (range) & $62(19-94)$ & $38(8-105)$ & 0.26 \\
\hline PN to stroke, mo, median (range) & $23(0.5-64)$ & NA & NA \\
\hline \multicolumn{4}{|l|}{ Stroke risk factors, mean (SD) } \\
\hline FSRP score & $6.6(4.7)$ & $5.7(4.2)$ & 0.69 \\
\hline \multicolumn{4}{|l|}{ Relevant comorbidities, $\mathrm{n}(\%, 95 \% \mathrm{Cl})$} \\
\hline Castleman disease & $3(33,12-65)$ & $13(16,10-26)$ & 0.29 \\
\hline \multicolumn{4}{|l|}{$\begin{array}{l}\text { Relevant POEMS features, } \\
\mathrm{n}(\%, 95 \% \mathrm{Cl})\end{array}$} \\
\hline PN & $9(100,70-100)$ & $81(100,95-100)$ & 0.99 \\
\hline Organomegaly & $6(67,35-88)$ & $47(58,47-68)$ & 0.59 \\
\hline Endocrinopathy & $9(100,70-100)$ & $74(91,83-96)$ & 0.31 \\
\hline Monoclonal gammopathy & $9(100,70-100)$ & $81(100,95-100)$ & 0.99 \\
\hline Skin changes & $7(78,45-94)$ & $61(75,65-83)$ & 0.98 \\
\hline Bone marrow plasmacytosis & $9(100,70-100)$ & $52(64,53-74)$ & $0.004^{+}$ \\
\hline \multicolumn{4}{|l|}{ Laboratory studies, median (range) } \\
\hline \multicolumn{4}{|l|}{ Serum } \\
\hline Platelets, $\times 10^{9} / \mathrm{L}$ & $571(295-783)$ & $400(78-926)$ & $0.002^{+}$ \\
\hline VEGF, pg/mL & $452(40-792)$ & $351(31-2861)$ & 0.93 \\
\hline $\mathrm{IL}-6, \mathrm{pg} / \mathrm{mL}$ & $6.9(1.7-23.2)$ & $4.8(0.92-40.6)$ & 0.81 \\
\hline M-spike, g/dL & $0.5(0.5-0.9)$ & $0.7(0.2-2)$ & 0.18 \\
\hline \multicolumn{4}{|l|}{ Bone marrow } \\
\hline$\%$ Cellularity & $50(30-70)$ & $50(20-90)$ & 0.77 \\
\hline \% Plasma cell & $5(3-10)$ & $5(1-20)$ & 0.3 \\
\hline
\end{tabular}

"p Value was calculated using Cox proportional hazards regression. +Significant.

POEMS = polyneuropathy, organomegaly, endocrinopathy, monoclonal gammopathy, and skin changes; $\mathrm{PN}=$ peripheral neuropathy; $\mathrm{Cl}=$ confidence interval; $\mathrm{F} / \mathrm{U}=$ follow-up: FSRP = Framingham Stroke Risk Profile; VEGF = vascular endothelial growth factor; IL-6 = interleukin-6.
RESULTS Demographic and stroke evaluation data. As of August 2008, a total of 208 patients were diagnosed with POEMS syndrome at our institution. The mean age at diagnosis was 51 years (SD 12 years) and there were $66 \%$ men. A total of 19 POEMS patients (9.2\%, 95\% CI 5.9-13.9) developed cerebral infarction, at a median age of 53 years (range 36-77; 12 men, $63 \%)$. The presence of traditional stroke risk factors, comorbidities, and results of serum studies around the time of initial event are summarized in table 1.

Retrospective cohort study. A subgroup of the overall cohort was analyzed to evaluate potential predictors of cerebral infarction. The study period between January 1, 2000, and August 1, 2008, was chosen to minimize any variability in diagnostic testing and treatment strategies used in caring for these patients. Of the 90 patients identified, 9 (10\%; 95\% CI 5.417.9) had a stroke at a median of 23 months (range 0.5-64 months) after the onset of peripheral neuropathy symptoms. The 5-year risk of stroke was estimated at $13.4 \%$ (95\% CI 3.8-22.0\%). The median clinical follow-up period after the onset of neuropathy, in the remaining 81 patients, was 38 months (range 8-105 months). None of the events occurred after successful treatment of the underlying syndrome. Table 2 summarizes patient demographic data, stroke risk profile, syndromic features, and the results of pertinent laboratory studies in the stroke and nonstroke subgroups (data recorded at the time of initial evaluation for POEMS syndrome). The majority of ischemic strokes were hemispheric alone $(89 \%)$ and within a single vascular territory (67\%). The breakdown of stroke mechanisms, by TOAST criteria, ${ }^{9}$ is presented in table 3.

A univariate analysis did not demonstrate a significant difference in FSRP scores, serum VEGF and IL-6 levels, or concurrent diagnosis of Castleman disease between the 2 groups. However, patients with cerebral infarctions did have higher blood platelet counts during their initial evaluation $(p=0.002)$. In addition, none of the patients in whom osteosclerotic lesions were the sole potential source of monoclonal proteins, without bone marrow involvement, had a cerebral infarction $(p=0.004)$. Patients were divided into 3 equal groups based on platelet counts (low, less than $336 \times 10^{9} / \mathrm{L}$; medium, 336-500 $\times$ $10^{9} / \mathrm{L}$; high, more than $500 \times 10^{9} / \mathrm{L}$ ) and the risk of cerebral infarction was assessed using Kaplan-Meier analyses. The 5-year risk of cerebral infarction in the low, medium, and high platelet count groups were $5 \%$, $8 \%$, and $29 \%$, respectively. Thrombocytosis ( $p=$ 0.015; hazard ratio 5.3, 95\% CI 1.4-25.3) and bone marrow plasmacytosis ( $p=0.007$; hazard ratio could not be estimated) remained predictive of cerebral infarction in our multivariable Cox regression model. 
Table 3 Spectrum of infarct topography in patients with POEMS syndrome (subgroup assessed January 1, 2000-August 31, 2008)

$\begin{array}{clll}\text { No. } & \begin{array}{l}\text { TOAST } \\ \text { classification* }\end{array} & \begin{array}{l}\text { Description } \\ \text { Infarction: left parietal lobe, right and left frontal cortex. Absent flow } \\ \text { signal in proximal left M1 segment. }\end{array} \\ 2 & \text { IV } & \text { IV } & \begin{array}{l}\text { Infarction: left parietal cortex. Absent flow in left M1 and marked } \\ \text { stenosis of right M1 segments. }\end{array} \\ \text { 3 } & \text { IV } & \begin{array}{l}\text { Infarction: right frontal semiovale in a borderzone distribution. } \\ \text { Absent flow-void within intracranial right ICA and tapered occlusion } \\ \text { of right cervical ICA, 17 mm from bifurcation (arterial dissection). }\end{array} \\ \text { Infarction: left parietal cortex. No major vessel occlusion or focal } \\ \text { h }\end{array}$

*Denotes TOAST classification: I = large-artery atherosclerosis; II = cardioembolism; III = small-artery occlusion; IV = other determined etiology; $\mathrm{V}=$ undetermined etiology. POEMS = polyneuropathy, organomegaly, endocrinopathy, monoclonal gammopathy, and skin changes; ICA = Internal carotid artery; $\mathrm{MCA}=$ Middle cerebral artery.

Imaging data. We evaluated the spectrum of infarct topography by reviewing all available imaging modalities. These included unilateral or bilateral cortical, border-zone, end-arterial, and major in-

\begin{tabular}{|c|c|c|c|}
\hline \multirow{2}{*}{$\begin{array}{l}\text { Table } 4 \\
\text { Reference }\end{array}$} & \multicolumn{3}{|c|}{$\begin{array}{l}\text { Summary of previously published case reports on cerebrovascular } \\
\text { disease in patients with POEMS syndrome }\end{array}$} \\
\hline & $\begin{array}{l}\text { Age, } \\
\text { y/sex }\end{array}$ & $\begin{array}{l}\text { Extracerebral infarction/ } \\
\text { event }\end{array}$ & Cerebral infarction/event \\
\hline 13 & $41 / \mathrm{M}$ & $\begin{array}{l}\text { Occlusion of superior } \\
\text { mesenteric and left renal } \\
\text { arteries }\end{array}$ & $\begin{array}{l}\text { Right frontoparietal infarction; } \\
\text { bilateral MCA stenosis, right ICA } \\
\text { narrowing }\end{array}$ \\
\hline 7 & $53 / F$ & $\begin{array}{l}\text { Stenosis of left subclavian and } \\
\text { superior mesenteric arteries }\end{array}$ & $\begin{array}{l}\text { Amaurosis fugax; occlusion of right ICA } \\
\text { and stenosis of left ICA }\end{array}$ \\
\hline 11 & $63 / F$ & PE & Amaurosis fugax; right ICA occlusion \\
\hline 5 & $42 / F$ & None & Large right MCA stroke \\
\hline 6 & $42 / \mathrm{M}$ & None & $\begin{array}{l}\text { Left } A C A / M C A \text { and MCA/PCA } \\
\text { watershed area infarction }\end{array}$ \\
\hline 6 & $48 / F$ & Left foot gangrene & Bilateral PCA territory infarction \\
\hline 6 & $52 / F$ & None & Left MCA/PCA watershed area infarction \\
\hline 4 & $49 / M$ & None & $\begin{array}{l}\text { Left subcortical infarct; bilateral M-1 } \\
\text { stenosis (left }>\text { right) }\end{array}$ \\
\hline 4 & $50 / F$ & None & $\begin{array}{l}\text { Bilateral BG infarction; bilateral M-1 } \\
\text { stenosis }\end{array}$ \\
\hline 12 & $59 / M$ & $\begin{array}{l}\text { Myocardial infarction, foot } \\
\text { gangrene }\end{array}$ & Recurrent stroke \\
\hline 8 & $32 / \mathrm{F}$ & None & Recurrent stroke \\
\hline
\end{tabular}

POEMS = polyneuropathy, organomegaly, endocrinopathy, monoclonal gammopathy, and skin changes; $\mathrm{MCA}=$ middle cerebral artery; $\mathrm{ICA}=$ internal carotid artery; $\mathrm{PE}=$ pulmonary embolism; $\mathrm{PCA}=$ posterior cerebral artery; $\mathrm{ACA}=$ anterior cerebral artery; $\mathrm{BG}=$ basal ganglia; $\mathrm{M}-1$ = first segment of MCA. tracranial arterial distribution cerebral infarctions. In contrast to previously reported data suggesting mainly the involvement of end arteries, our angiographic results demonstrated a number of abnormalities within the cervical and proximal intracranial vasculature (table 3 ).

DISCUSSION Our study suggests that about 1 out every 10 patients with POEMS has a cerebral infarction, at a relatively young age. We also found that traditional stroke risk factors such as age, diabetes, hypertension, smoking, or cardiac arrhythmias were not significantly different between the stroke and nonstroke subgroups. An elevated blood platelet count and evidence of plasma cell proliferation on bone marrow biopsy, however, were associated with an increased risk of stroke.

Cases of cerebral infarction in patients with POEMS syndrome have been sporadically described in the literature. ${ }^{3-8,11-16}$ There are several theories regarding the potential etiologies, risk factors, and involved vascular territories. Yet, due to the rarity of this syndrome, all such speculation has been based on case reports comprising 1-3 patients and whether a direct association exists between the diagnosis of POEMS syndrome and occurrence of cerebral infarction remains unclear. A summary of these and other studies is provided in table 4 .

At the time of cerebral infarction, our patients were younger than the typical age range reported in stroke registries. ${ }^{17}$ Traditional and modifiable risk factors such as smoking, hypertension, atrial fibrillation, and diabetes mellitus occurred in similar frequencies to those typically reported in these population-based studies. ${ }^{18}$ More importantly, these risk factors were equally distributed between patients with POEMS syndrome who had a stroke and those who did not. At this point, it appears reasonable to invoke a direct association between POEMS syndrome and cerebral infarction.

In terms of the involved vascular segments, it is now clear that end arteries and borderzone areas are not the sole territories at risk for infarction. In our study, we showed a wide spectrum of infarct topography and abnormalities within the cervical and proximal intracranial vasculature. The preponderance of multivessel stenotic lesions and presence of arterial dissection in individuals without atherosclerotic risk factors suggest that POEMS syndrome typically leads to a structural vascular anomaly. This vasculopathy is likely noninflammatory in nature as suggested by the benign CSF characteristics in these patients. Further evidence to this effect would require pathologic specimens, which are currently lacking. 
There are some limitations to this study. Aside from the retrospective nature of the study, the cohort is relatively small. Yet, given the rarity of POEMS syndrome, it represents the largest cohort of patients with POEMS syndrome with cerebral infarction from a single institution. The small number of endpoints precludes definitive analysis of predictors of outcome. The possibility of referral bias is also present given that patients with more severe types of this uncommon syndrome may be more likely to be referred to our institution. Nevertheless, none of these potential limitations negates the validity of our results.

\section{AUTHOR CONTRIBUTIONS}

Statistical analysis was conducted by S.A. Dupont with guidance from Tanya L. Hoskin (Biomedical Statistics and Information, Mayo Clinic)

\section{ACKNOWLEDGMENT}

The authors thank Tanya L. Hoskin (Biomedical Statistics and Information, Mayo Clinic) for statistical support.

\section{DISCLOSURE}

Dr. Dupont, Dr. Dispenzieri, and Dr. Mauermann report no disclosures. Dr. Rabinstein serves as a Section Editor for Current Treatment Options in Neurology and Neurocritical Care. Dr. Brown receives royalties from publishing Handbook of Stroke (Lippincott Williams \& Wilkins, 2005); serves on the Board of Directors of the Neilsen Foundation; and receives research support from the NIH/NINDS [5R01NS028492 (PI), 5R01NS039512 (co-I), and 5R01NS039987 (co-I)].

Received March 16, 2009. Accepted in final form July 27, 2009.

\section{REFERENCES}

1. Dispenzieri A, Kyle RA, Lacy MQ, et al. POEMS syndrome: definitions and long-term outcome. Blood 2003; 101:2496-2506.

2. Santoro L, Manganelli F, Bruno R, Nolano M, Provitera V, Barbieri F. Sural nerve and epidermal vascular abnormalities in a case of POEMS syndrome. Eur J Neurol 2006;13:99-102.

3. Bova G, Pasqui AL, Saletti M, Bruni F, Auteri A. POEMS syndrome with vascular lesions: a role for interleukin-1 beta and interleukin-6 increase: a case report. Angiology 1998; 49:937-940.
4. Garcia T, Dafer R, Hocker S, Schneck M, Barton K, Biller J. Recurrent strokes in two patients with POEMS syndrome and Castleman's disease. J Stroke Cerebrovasc Dis 2007;16:278-284.

5. Huang J, Wang L, Zhou W, Jin J. Hyaline vascular Castleman disease associated with POEMS syndrome and cerebral infarction. Ann Hematol 2007;86:59-61.

6. Kang K, Chu K, Kim D-E, Jeong S-W, Lee J-W, Roh J-K. POEMS syndrome associated with ischemic stroke [see comment]. Arch Neurol 2003;60:745-749.

7. Lesprit P, Authier FJ, Gherardi R, et al. Acute arterial obliteration: a new feature of the POEMS syndrome? Medicine 1996;75:226-232.

8. Rossler M, Kiessling B, Klotz JM, Langohr HD. [Recurrent cerebral ischemias due to cerebral vasculitis within the framework of incomplete POEMS syndrome with Castleman disease.] Nervenarzt 2004;75:790-794.

9. Adams HP, Jr., Bendixen BH, Kappelle LJ, et al. Classification of subtype of acute ischemic stroke: definitions for use in a multicenter clinical trial: TOAST: Trial of Org 10172 in Acute Stroke Treatment. Stroke 1993;24:35-41.

10. D'Agostino RB, Wolf PA, Belanger AJ, Kannel WB. Stroke risk profile: adjustment for antihypertensive medication: The Framingham Study. Stroke 1994;25:40-43.

11. Erro ME, Lacruz F, Aymerich N, et al. Acute carotid obliteration: a new vascular manifestation in POEMS syndrome. Eur J Neurol 2003;10:383-384.

12. Forster A, Muri R. [Recurrent cerebrovascular insult: manifestation of POEMS syndrome?] Schweizerische Medizinische Wochenschrift. J Suisse Med 1998;128:1059-1064.

13. Lee MR, Choi HJ, Lee EB, Baek HJ. POEMS syndrome complicated by extensive arterial thromboses. Clin Rheumatol 2007;26:1989-1992.

14. Manning WJ, Goldberger AL, Drews RE, et al. POEMS syndrome with myocardial infarction: observations concerning pathogenesis and review of the literature. Semin Arthritis Rheum 1992;22:151-161.

15. Soubrier M, Guillon R, Dubost JJ, et al. Arterial obliteration in POEMS syndrome: possible role of vascular endothelial growth factor. J Rheumatol 1998;25:813-815.

16. Zenone T, Bastion $Y$, Salles G, et al. POEMS syndrome, arterial thrombosis and thrombocythaemia. J Intern Med 1996;240:107-109.

17. Centers for Disease Control and P. Prevalence of strokeUnited States, 2005. MMWR Morb Mortal Wkly Rep 2007;56:469-474.

18. Romero JR. Prevention of ischemic stroke: overview of traditional risk factors. Curr Drug Targets 2007;8:794-801. 